Title:

\title{
Differential effect of ethanol intoxication on peripheral markers of cerebral injury in murine blunt TBI
}

Authors:

\author{
Zhenghui $\mathrm{Li}^{1,2,{ }^{*}}$, Jin Zhang ${ }^{1,{ }^{*}}$, Steffen Halbgebauer ${ }^{1}$, Akila \\ Chandrasekar $^{1,+}$, Rida Rehman ${ }^{1}$, Albert Ludolph ${ }^{1,3}$, Tobias Boeckers ${ }^{3,4}$, \\ Markus Huber-Lang ${ }^{5}$, Markus Otto ${ }^{1}$, Francesco Roselli ${ }^{1,3, \#}$, Florian olde \\ Heuvel ${ }^{1, \#}$
}

Affiliations: 1. Dept. of Neurology, Ulm University, ZBMF - Helmholtzstrasse 8/1, $89081 \mathrm{Ulm}$, Germany

2. Department of Neurosurgery, Kaifeng Central Hospital, Kaifeng, 475000 Henan China

3. German Center for Neurodegenerative Diseases (DZNE), Ulm, Germany

4. Institute of Anatomy and Cell Biology, Ulm University, Ulm, Germany, M24, AlbertEinstein Allee 11, 89081 Ulm, Germany

5. Institute of Clinical and Experimental Trauma-Immunology, University Hospital, ZBMF - Helmhotzstrasse 8/1, 89081 Ulm, Germany

* Co-first authors

\# Co-senior authors

十 Present address: Zoological Institute Braunschweig, Cellular Neurobiology Biozentrum, Spielmannstrasse 7, 38106 Braunschweig

\author{
Corresponding author: Francesco Roselli, \\ Center for Biomedical Research (ZBF) \\ Helmholtzstrasse 8-89081 UIm (DE) \\ Phone: 0049-0731-500-63147 \\ Email: francesco.roselli@uni-ulm.de
}


Key Words: Traumatic brain injury, ethanol, biomarkers, NFL, NSE, Claudin-5

\section{Abstract}

Blood-based biomarkers have proven to be a reliable measure of traumatic brain injury (TBI) severity and outcome, in both murine models and patients. In particular, neuron-specific enolase (NSE) and neurofilament light (NFL) have been investigated in the clinical setting post injury. Ethanol intoxication (EI) remains a significant comorbidity in TBI, with $30-40 \%$ of patients having a positive blood alcohol level (BAC) post TBI. The effect of ethanol on bloodbased biomarkers on the prognosis and diagnosis of TBI remain unclear. In this study, we investigated the effect of El on NSE and NFL and their correlation with blood-brain barrier (BBB) integrity in a murine model of TBI. We have used ultra-sensitive single molecule array technology (SIMOA) and ELISA methods to measure NFL, NSE and Claudin-5 concentrations in plasma 3h post TBI. We showed that both NFL and NSE were increased 3h post TBI. However, ethanol blood concentrations only showed an inverse correlation with NSE, but not NFL. Claudin-5 levels were increased post injury, but no difference was detected in El. The Claudin-5 increase post TBI was correlated with NFL, but not with NSE. Thus, the data indicate that ethanol has a confined effect on biomarker release in the bloodstream and neuronal biomarkers reflect a different pathophysiology upon TBI. 


\section{Introduction}

Blood based biomarkers serve as a promising candidate to define neuronal and glial damage upon Traumatic Brain Injury (TBI; 1,2). In particular, serum neuron-specific enolase (NSE) have been found to be increased in head trauma in patients $(3,4)$ and NSE elevation was inversely correlated with the Glasgow Coma Scale score (5). Serum NSE levels were demonstrated to be predictive of TBI outcome (4). Alternative to NSE, Neurofilament light (NFL), which is a marker for axonal damage and is upregulated in various neurodegenerative disorders $(6,7)$, has been recently shown to be upregulated in blood and CSF samples of TBI patients $(8,9)$.

Peripheral biomarkers of neuronal damage have been infrequently applied to experimental models of TBI, in particular in murine models. NSE has been used as a proxy for the loss of neuronal integrity $(10,11)$; plasma levels of NFL have been used to monitor the progression of neurodegeneration in murine models of Alzheimer's disease (12) and it has been recently extended to applications in murine TBI (13).

Despite promising data from human and mouse cohort studies, several aspects of the application of peripheral biomarkers in the diagnosis and prognosis of TBI remain unclear. In particular, it has not been explored how important comorbidities interfere with the levels of peripheral biomarkers. In this context, ethanol intoxication is known to be one of the most common comorbidity in TBI, with $30-40 \%$ of patients showing a positive blood alcohol concentration (BAC) (14). The effect of BAC on patients' survival and recovery remains controversial: positive BAC at the time of TBI has been associated with a better prognosis $(15,16,17,18,19)$, but neutral or detrimental effects are also reported $(20,21,22)$. In experimental TBI settings, ethanol proved to decrease TBI-induced neuroinflammatory effects and neuronal deficits $(23,24,25,26)$, although not in all studies $(27,28)$. In the present 
study, we have explored the effects of ethanol intoxication on peripheral biomarkers associated with TBI in a post-hoc analysis of murine samples from previous studies. Our goals were to determine if ethanol intoxication would affect the rise in brain damage markers upon TBI, focusing on the neuronal damage indicators NSE and NFL and on the vascular integrity marker Claudin-5. Here we show an increase in plasma levels of neuronal biomarkers NSE and NFL upon TBI. Blood ethanol concentrations display an inverse correlation with NSE but not with NFL. Notably, NFL levels directly correlated with Claudin-5, but not with NSE. These findings suggest different modes of biomarker release to the bloodstream after injury and the selective effect of ethanol on a subset of biomarkers used in TBI.

\section{Material \& Methods}

Animals, Traumatic brain injury model and Ethanol treatment

This is a post-hoc, hypothesis-driven analysis of blood samples obtained in the context of previous studies $(23,24,25,26)$; the investigation of these samples has never been reported before and it has been undertaken, in accordance to the 3R-principle, to reduce the number of mice employed in animal experimental and to maximize the scientific output from animal sacrifice.

These experiments have been approved by the Regierungspräsidium Tübingen with animal license no. 1222, with successive integrations, and by the Ulm University animal experimentation oversight committee.

B6-SIL were bred locally (UIm University) under standard husbandry conditions $\left(24^{\circ} \mathrm{C}, 60-\right.$ $80 \%$ humidity, $12 / 12$ light/dark cycle, with ad libitum access to food and water). Experimental traumatic brain injury was performed as previously reported $(23,24,25,26)$. 
Briefly, after administration of buprenorphine $(0.1 \mathrm{mg} / \mathrm{kg}$ by subcutaneously injection) and under sevoflurane anesthesia (2,5\% in 97,5\% 02), male mice aged $60-90$ days were subject to closed weight-drop TBI. Animals were then manually positioned in the weight-drop apparatus and TBI was delivered by a $333 \mathrm{~g}$ impactor free-falling from a $2 \mathrm{~cm}$ distance, targeting the parietal bone (29). Immediately after the experimental TBI, animals were administered $100 \% 02$ and were monitored for the apnea time. For sham surgery, mice were subjected to the same procedures and treatments (anesthesia, skin opening and closure, handling, positioning in the TBI apparatus), but no trauma was delivered. Ethanol was administered by oral gavage: $400 \mu$ l of $32 \%$ ethanol solution in saline were administered $30 \mathrm{~min}$ before the procedures. Four experimental groups were considered: salineadministered, subjected to sham surgery (saline-sham, SS), saline-administered, subjected to TBI (saline-TBI, ST), ethanol administered, subjected to sham surgery (ethanol-sham, ES), ethanol administered, subjected to TBI (ethanol-TBI; ST).

\section{Blood sampling and plasma preparation}

Three hours after trauma, animals were subject to xylazine/ketamine terminal anesthesia; blood was collected by right ventricular puncture using a 1-ml syringe equipped with a $24 \mathrm{G}$ needle and quickly transferred to a vial containing EDTA as anticoagulant. From each mouse, $400-500 \mu \mathrm{l}$ of blood $(200-300 \mu \mathrm{l}$ of serum $)$ was collected. Plasma samples were prepared by centrifuging the EDTA vials for $5 \mathrm{~min}$ at $800 \mathrm{~g}$ at $4^{\circ} \mathrm{C}$, the supernatant was collected and centrifuged again for $2 \mathrm{~min}$ at $13.000 \mathrm{~g}$ at $4^{\circ} \mathrm{C}$. Plasma was aliquoted and stored at $-80^{\circ} \mathrm{C}$ until use. 
The ethanol blood assay was performed according to manufacturer's instructions (Abcam). Briefly, plasma was diluted in $\mathrm{ddH}_{2} \mathrm{O}$ (500x for ethanol samples and $10 \mathrm{x}$ for the saline samples). Samples were added to a 96-well plate, a mastermix of ethanol probe, ethanol enzyme mix and ethanol assay buffer was added and incubated for $30 \mathrm{~min}$ at $37^{\circ} \mathrm{C}$. The optical density (OD) 450nm was measured by using a colorimetric detection (Fluostar Optima, BMG Labtech) and concentrations were calculated with the standard curve.

\section{SIMOA}

Single molecule array quantification of plasma Neurofilament light chain (Quanterix) was performed as previously reported (30) and in agreement with manufacturer's instructions. Mouse serum $(5 \mu l)$ was diluted 1:20 before the assay.

\section{ELISA}

Enzyme-linked immuno-sorbent assays for Neuron-specific Enolase (NSE) and Claudin-5 were performed according to manufacturer's instructions (mouse ENO2/NSE (CLIA) ELISA Kit, LSbio; mouse Claudin-5(ELISA Kit, Cusabio). Briefly, 100 $\mu$ l of diluted samples (NSE: 1:10; Claudin-5: 1:2; diluted in sample diluent) or standards were added to the well and incubated $90 \mathrm{~min}$ at $37^{\circ} \mathrm{C}$, followed by aspiration of the liquid and directly followed by $100 \mu \mathrm{l}$ of $1 \mathrm{x}$ biotinylated detection antibody working solution for 1 hour at $37^{\circ} \mathrm{C}$. The wells were aspirated and then washed $3 x$ by adding $350 \mu$ of washing buffer to each well for $2 \mathrm{~min}$ at RT, after which $100 \mu$ l of $1 \times$ HRP conjugate was added to the well and incubated $30 \mathrm{~min}$ at $37^{\circ} \mathrm{C}$. The wells were aspirated and washed $5 x$ with $350 \mu$ l of washing buffer for 2 min each. Finally, $100 \mu \mathrm{l}$ of working substrate solution was added to each well and incubated for $5 \mathrm{~min}$ at $37^{\circ} \mathrm{C}$ 
(for the Claudin-5 ELISA 50 $\mu$ l of stop solution was added) after which the relative light units (RLU) (for NSE) or OD at 450nm (for Claudin-5) were measured by using a microplate luminometer (Luminoscan Ascent, Thermo Scientific). Concentrations were calculated according to the standard curve.

\section{Data analysis}

Statistical analysis was performed using Graphpad prism version 8 software. Grouped analysis for the ELISA and SIMOA data was performed by using the Kruskal-Wallis test with Dunn's multiple correction. Correlation assays were performed between treatment groups and different analytes to assess the relationship. Analysis of covariance (ANCOVA) was undertaken by comparing linear regression slopes of treatment groups with Tukey multiple correction. Data was depicted in graphs as median, 25 th to 75 th percentile (box), min to max (whiskers) or correlation with linear regression. Data in the text were depicted as median (min to max). Statistical significance was set at $\mathrm{p}<0.05$. 


\section{Results}

Blood Ethanol concentration is not affected by TBI after oral binge

First, we established the concentration of ethanol in plasma upon single "oral binge" with or without concomitant TBI. For this, mice were pretreated with saline or ethanol $(5 \mathrm{~g} / \mathrm{kg}) 30$ min before either TBI or sham surgery; ethanol concentrations were measured $3 \mathrm{~h}$ after the trauma. Four experimental groups were therefore considered: saline-sham (SS; $N=8$ ), ethanol-sham-S (ES; N=14), saline TBII (ST; N=24) and ethanol-TBI (ET; N=17). The KruskalWallis test showed a significant effect in ethanol concentrations between treatment groups ( $p<0.0001$; Fig 1). The post-hoc comparison (Dunn's corrected) revealed a significant difference, predictably, between SS and ES (median-range: 8.9 (0 to 84.0 ) $\mu \mathrm{mol}$ vs 4208.9 (1279.1 to 7661.6) $\mu \mathrm{mol} ; \mathrm{p}=0.0003 ; \mathrm{Fig} 1$ ) and between ST and ET (median-range 13.5 ( 0 to 291.0) $\mu \mathrm{mol}$ vs 3832.1 (2186.5 to 7753.9) $\mu \mathrm{mol} ; \mathrm{p}<0.0001$; Fig 1) but ES and ET showed a comparable plasma ethanol concentrations ( $p>0.9999 ;$ Fig 1$)$. These findings suggest that TBI does not per se affect the clearance of ethanol after "oral binge".

Ethanol intoxication blunts NSE but not NFL upregulation after TBI. Next we set out to investigate the effect of ethanol intoxication on two peripheral biomarkers of neuronal injury after TBI, namely NFL and NSE concentrations. For the NFL assessment, Kruskal-Wallis Test revealed a significant effect between treatment groups ( $p<0.0001$; Fig $2 A)$. The posthoc comparison (Dunn's corrected) showed that ethanol alone, in absence of trauma, did not affect the NFL concentrations in plasma (median-range SS: 78.3 (35.8 to 226.2) pg/ml vs ES: 190.3 (20.9 to 1112.3 ) pg/ml; $p>0.9999$; Fig 2A). TBI showed a significant upregulation in comparison to baseline (median-range SS: 78.3 (35.8 to 226.2) pg/ml vs ST: 969.4 (76.7 to 3276) $\mathrm{pg} / \mathrm{ml} \mathrm{p}=0.0005$; Fig 2A). Ethanol treatment prior to TBI showed only a trend towards 
lower concentrations in comparison to the ST group (ST: 969.4 (76.7 to 3276$) \mathrm{pg} / \mathrm{ml}$ vs ET:

608.8 (238.5 to 1541.2 ) pg/ml; $p>0.9999 ; \mathrm{Fig} 2 \mathrm{~A}$ ). Interestingly, concentrations of plasma ethanol were completely uncorrelated to NFL concentrations (in ET group $\mathrm{R}^{2}=0.0170 ; p=$ 0.6306; Fig 2B).

Likewise, the Kruskal-Wallis Test applied to the NSE dataset revealed a significant effect between treatment groups ( $p=0.0232$; Fig 3A). The post-hoc comparison (Dunn's corrected) revealed that ethanol alone showed no effect on NSE plasma concentrations (SS: 144.0 (98.6 to 291.5 ) vs ES: 191.9 (106.0 to 323.9); $p$ > 0.9999; Fig 3A). TBI showed a significant effect in comparison to sham (median-range SS: 144.0 (98.6 to 291.5) vs ST: 215.7 (140.8 to 644.1); p $=0.0295 ; \mathrm{Fig} 3 \mathrm{~A})$. However, ethanol treatment before TBI showed no significant difference between TBI on its own (median-range ST: 215.7 (140.8 to 644.1$) \mathrm{pg} / \mathrm{ml}$ vs ET: 202.0 (65.9 to 380.5) pg/ml; $p$ > 0.9999; Fig 3A), but a significant inverse correlation was found between ethanol concentrations and NSE concentrations in the ET group $\left(R^{2}=0.4069 ; p=0.0078\right.$; Fig 3B)

Notably, the values of blood ethanol, NSE and NFL concentrations displayed a substantial variability, despite the use of inbred mouse lines and standardized equipment. Surprisingly, when we tested if the concentrations of the two neuronal damage markers were correlated, the ANCOVA revealed no difference between the slopes of the treatment groups $(F=$ $0.4236 ; p=0.7368$ ) and correlation within the groups was poor (NSE vs NFL SS: $R^{2}=0.0503$; $p=0.6306, E S: R^{2}=0.0003 ; p=0.9541, S T: R^{2}=0.0918 ; p=0.1600, E T: R^{2}=0.0118 ; p=$ 0.6893; Fig 3C).

Thus, the amount of ethanol affects NSE plasma concentrations but not NFL plasma concentrations upon TBI, possibly indicating either an effect on the pathophysiology of the release of these biomarkers or an effect on their transport to the blood. 
NFL levels in the plasma is correlated to blood brain barrier disruption

Furthermore, we sought to identify if ethanol modified the disruption of blood-brain-barrier caused by TBI, and if such a disruption influenced NSE or NFL plasma concentrations. To this end we assessed Claudin-5 concentrations in our samples by ELISA. Plasma Claudin-5 concentrations have been repeatedly used as markers of loss of vascular integrity upon TBI $(31,32)$. The Kruskal-Wallis Test revealed a significant difference between treatment groups ( $p=0.0047 ;$ Fig 4A). The post-hoc analysis (Dunn's corrected) showed no significant effect of ethanol by itself (median-range SS: 111.8 (46.1 to 168.7 ) $\mathrm{pg} / \mathrm{ml}$ vs ES: 64.8 (0 to 180.0) $\mathrm{pg} / \mathrm{ml} ; \mathrm{p}>0.9999 ; \mathrm{Fig} 4 \mathrm{~A})$. TBI resulted in an increase of plasma Claudin-5 concentrations compared to ES (ES: 64.8 (0 to 180.0$) \mathrm{pg} / \mathrm{ml}$ vs ST: 161.2 (77.9 to 237.0 ) pg/ml; $\mathrm{p}=0.0157$;

Fig 4A). However, ethanol did not alter the plasma Claudin-5 concentrations upregulated by TBI (ST: 161.2 (77.9 to 237.0 ) pg/ml vs ET: 178.0 (26.4 to 444.7) pg/ml; p > 0.9999; Fig 4A). When correlating the concentrations of Claudin-5 ET treatment group to the amount of ethanol in the same group, we identified no significant correlation between the concentrations of ethanol and the concentrations of Claudin- 5 in the plasma $\left(R^{2}=0.0215 ; p\right.$ $=0.5747$; Fig 4B), suggesting that the amount of ethanol in the blood does not alter the disruption of blood-brain-barrier.

Next, we sought to identify the eventual correlation between the disruption of blood-brainbarrier and the concentrations of neuronal damage biomarkers. Analysis of covariance (ANCOVA) revealed no significant differences between the slopes of treatment groups $(\mathrm{F}=$ 0.9541; $p=0.4207)$. In fact, correlation of NSE and Claudin-5 concentrations was very poor in each of the four treatment groups $\left(S S: R^{2}=0.0379 ; p=0.6757, E S: R^{2}=0.0001 ; p=0.9716\right.$, $S T: R^{2}=0.0470 ; p=0.3455, E T: R^{2}=0.1597 ; p=0.1251 ;$ Fig $\left.5 A\right)$. However, when correlating 
NFL with Claudin-5 analysis of covariance (ANCOVA) showed a significant difference in treatment groups $(F=3.157 ; p=0.0320)$; post-hoc analysis revealed a significant correlation in the ST group $\left(R^{2}=0.2545 ; p=0.0276\right.$; Fig $\left.5 B\right)$, but not in the other treatment groups (SS: $R^{2}=0.5546 ; p=0.0548, E S: R^{2}=0.0512 ; p=0.4571, E T: R^{2}=0.0136 ; p=0.6785 ;$ Fig $5 B$ ) and $a$ significant difference between the ST and ET group $(p=0.0303)$. Thus, the severity of blood brain barrier disruption correlates with NFL concentrations but this is not true for NSE. 


\section{Discussion}

Here we have demonstrated that TBI induces the elevation of the peripheral damage related neuronal and vascular biomarkers (NSE, NFL and Claudin-5) and that ethanol appears to dose-dependently decrease NSE but not NFL or Claudin-5 concentrations in serum samples. Interestingly, even in absence of ethanol modulation, NFL serum concentrations correlated with the concentrations of Claudin-5, but not with NSE concentrations. Thus, our data suggest that i) ethanol intoxication reduces NSE concentrations, but not necessarily the overall acute burden of neurodegeneration as explored by NFL, and ii) concentrations of NFL, but not of NSE, correlates with the degree of disruption of the blood-brain-barrier (BBB).

Both NSE and NFL have been extensively investigated as markers of neuronal damage in TBI, displaying an overall significant elevation upon brain trauma $(1,4,5,33,34)$. Nevertheless, the two markers do not appear to represent the same type of pathogenic process. Whereas NSE elevation peaks early after TBI, NFL levels keep increasing over several days (1) and their levels, although broadly elevated, do not always display a close correlation $(1,35)$. This is not completely surprising when considering the different cell biology of the two markers: NFL is a constituent of the cytoskeleton and is highly enriched in large, myelinated axons, from where a small amount of NFL is released even in normal conditions $(36,37)$. NSE is, on the other hand, an abundant soluble cytoplasmic protein expressed in neurons and in glial cells (38). Thus, whereas NFL is a better marker of axonal damage (39), NSE may reflect neuronal integrity. As a consequence, ethanol appears to be effective in limiting acute neuronal damage in TBI mouse models (in agreement with previous histological data; 10,24), but less effective (or ineffective) in protecting axonal tracts. These findings may be in accordance 
with activity-dependent mechanisms that may prevent neuronal degeneration, but may be unrelated to the dismantling of long-range axons. This observation may explain why ethanol intoxication in TBI patients appears to be protective especially in patients with penetrating injuries and much less in those with diffuse axonal injury (40).

Claudin-5 is a tight junction protein highly expressed in endothelial cells, where it contributes to the integrity of the BBB (41). Serum levels of Claudin-5 are considered a promising marker of BBB integrity $(42,43)$. Although ethanol appears to decrease the inflammatory response induced by TBI (23), it does not affect the peripheral elevation in soluble Claudin-5 triggered by TBI. This finding is in agreement with the previous report of the lack of effect of ethanol on the downregulation of IL-25, a central regulator of BBB integrity, upon trauma (26). Thus, ethanol appears to have a restricted effect on peripheral biomarkers, reducing NSE without affecting NFL or Claudin-5 and thus possibly affecting neuronal survival, but not axonal damage and vascular integrity.

Interestingly, Claudin-5 concentrations directly correlated with NFL concentrations, but not with NSE concentrations upon trauma (with or without ethanol). This finding suggests that whereas the appearance of NFL in serum is facilitated by the increase in permeability of the BBB, serum NSE levels increase irrespective of BBB integrity. In fact, clearance of NSE from the CNS is only mildly related to BBB markers in TBI patients (44). It is tempting to speculate that other systems, such as the recently-identified glymphatic system, may be involved in the BBB-independent transfer of NSE from the brain to the blood. This finding further underscores how NFL and NSE may explore distinct aspects of the pathophysiology of TBI. 
As a potential limitation of this study, it is worth noticing that we have used a relatively small number of biomarkers to investigate the effect of ethanol on biomarker prognosis. Various biomarkers might display distinct responses to ethanol upon TBI, like inflammatory mediators (45) or astrocyte-enriched proteins (46). The small number of biomarkers explored was due to the comparatively small volume of serum recovered from each mouse and the volume required by ELISA assays. A more widespread use of high-sensitivity SIMOA systems will allow in future the in-depth exploration of biomarkers of TBI in murine models. A second limitation may be constituted by the exploratory, retrospective design of this study; although operators and procedures were similar across several studies, unforeseen biases may contribute to the large variability of the NSE and NFL values. Therefore, this study should be considered as an entry point for further, dedicated, prospective studies using multiple biomarkers to address the effect of ethanol on specific cellular subpopulations and specific pathogenetic cascades. 


\section{Acknowledgement}

This work has been supported by the Deutsche Forschungsgemeinschaft as part of the Collaborative Research Center 1149 "Danger Response, Disturbance Factors and Regenerative Potential after Acute Trauma". FR is also supported by the ERANET-NEURON initiative "External Insults to the Nervous System" as part of the MICRONET consortium and by the Baustein program of the Medical Faculty of Ulm University. Technical support by Thomas Lenk was highly appreciated.

\section{Conflict}

The authors declare no conflict of interest. 


\section{References}

1. Thelin E, Al Nimer F, Frostell A, Zetterberg H, Blennow K, Nyström H, Svensson $M$, Bellander BM, Piehl F, Nelson DW. A Serum Protein Biomarker Panel Improves Outcome Prediction in Human Traumatic Brain Injury. J Neurotrauma. 2019 Oct $15 ; 36(20): 2850-2862$.

2. Agoston DV, Shutes-David A, Peskind ER. Biofluid biomarkers of traumatic brain injury. Brain Inj. 2017;31(9):1195-1203.

3. Ruslin M, Wolff J, Yusuf HY, Arifin MZ, Boffano P, Forouzanfar T. Use of neuronspecific enolase to predict mild brain injury in motorcycle crash patients with maxillofacial fractures: A pilot study. Chin J Traumatol. 2019 Feb;22(1):47-50.

4. Meric E, Gunduz A, Turedi S, Cakir E, Yandi M. The prognostic value of neuronspecific enolase in head trauma patients. J Emerg Med. 2010 Apr;38(3):297-301.

5. Guzel A, Er U, Tatli M, Aluclu U, Ozkan U, Duzenli Y, Satici O, Guzel E, Kemaloglu S, Ceviz A, Kaplan A. Serum neuron-specific enolase as a predictor of short-term outcome and its correlation with Glasgow Coma Scale in traumatic brain injury. Neurosurg Rev. 2008 Oct;31(4):439-44; discussion 444-5.

6. Soylu-Kucharz R, Sandelius Å, Sjögren M, Blennow K, Wild EJ, Zetterberg H, Björkqvist M. Neurofilament light protein in CSF and blood is associated with 
neurodegeneration and disease severity in Huntington's disease R6/2 mice. Sci Rep. 2017 Oct 26;7(1):14114.

7. Rossi D, Volanti P, Brambilla L, Colletti T, Spataro R, La Bella V. CSF neurofilament proteins as diagnostic and prognostic biomarkers for amyotrophic lateral sclerosis. J Neurol. 2018 Mar;265(3):510-521.

8. Shahim P, Gren M, Liman V, Andreasson U, Norgren N, Tegner $Y$, Mattsson N, Andreasen N, Öst M, Zetterberg H, Nellgård B, Blennow K. Serum neurofilament light protein predicts clinical outcome in traumatic brain injury. Sci Rep. 2016 Nov $7 ; 6: 36791$.

9. Guedes VA, Kenney K, Shahim P, Qu BX, Lai C, Devoto C, Walker WC, Nolen T, DiazArrastia R, Gill JM; CENC Multisite Observational Study Investigators. Exosomal neurofilament light: A prognostic biomarker for remote symptoms after mild traumatic brain injury? Neurology. 2020 Jun 9;94(23):e2412-e2423.

10. Goodman MD, Makley AT, Campion EM, Friend LA, Lentsch AB, Pritts TA. Preinjury alcohol exposure attenuates the neuroinflammatory response to traumatic brain injury. J Surg Res. 2013 Oct;184(2):1053-8.

11. Yang Y, Zhang XJ, Zhang C, Chen R, Li L, He J, Xie Y, Chen Y. Loss of neuronal CD200 contributed to microglial activation after acute cerebral ischemia in mice. Neurosci Lett. 2018 Jun 21;678:48-54.

12. Mattsson N, Andreasson U, Zetterberg H, Blennow K; Alzheimer's Disease Neuroimaging Initiative. Association of Plasma Neurofilament Light With Neurodegeneration in Patients With Alzheimer Disease. JAMA Neurol. 2017 May $1 ; 74(5): 557-566$ 
13. Cheng WH, Stukas S, Martens KM, Namjoshi DR, Button EB, Wilkinson A, Bashir A, Robert J, Cripton PA, Wellington CL. Age at injury and genotype modify acute inflammatory and neurofilament-light responses to mild CHIMERA traumatic brain injury in wild-type and APP/PS1 mice. Exp Neurol. 2018 Mar;301(Pt A):26-38.

14. Bjarkø VV, Skandsen T, Moen KG, Gulati S, Helseth E, Nilsen TIL, Vik A. Time of Injury and Relation to Alcohol Intoxication in Moderate-to-Severe Traumatic Brain Injury: A Decade-Long Prospective Study. World Neurosurg. 2019 Feb;122:e684-e689.

15. Brigode W, Cohan C, Beattie G, Victorino G. Alcohol in Traumatic Brain Injury: Toxic or Therapeutic? J Surg Res. 2019 Dec;244:196-204.

16. Raj R, Mikkonen ED, Siironen J, Hernesniemi J, Lappalainen J, Skrifvars MB. Alcohol and mortality after moderate to severe traumatic brain injury: a meta-analysis of observational studies. J Neurosurg. 2016 Jun;124(6):1684-92.

17. Brennan JH, Bernard S, Cameron PA, Rosenfeld JV, Mitra B. Ethanol and isolated traumatic brain injury. J Clin Neurosci. 2015 Sep;22(9):1375-81.

18. Raj R, Skrifvars MB, Kivisaari R, Hernesniemi J, Lappalainen J, Siironen J. Acute alcohol intoxication and long-term outcome in patients with traumatic brain injury. J Neurotrauma. 2015 Jan 15;32(2):95-100.

19. Mohseni S, Bellander BM, Riddez L, Talving P, Thelin EP. Positive blood alcohol level in severe traumatic brain injury is associated with better long-term functional outcome. Brain Inj. 2016;30(10):1256-1260.

20. Shandro JR, Rivara FP, Wang J, Jurkovich GJ, Nathens AB, Mackenzie EJ. Alcohol and risk of mortality in patients with traumatic brain injury. J Trauma. 2009;66(6):15841590. 
21. Yue JK, Ngwenya LB, Upadhyayula PS, Deng H, Winkler EA, Burke JF, Lee YM, Robinson CK, Ferguson AR, Lingsma HF, Cnossen MC, Pirracchio R, Korley FK, Vassar MJ, Yuh EL, Mukherjee P, Gordon WA, Valadka AB, Okonkwo DO, Manley GT; TRACKTBI Investigators. Emergency department blood alcohol level associates with injury factors and six-month outcome after uncomplicated mild traumatic brain injury. J Clin Neurosci. 2017 Nov;45:293-298.

22. Ding Q, Wang Z, Shen M, Su Z, Shen L. Acute Alcohol Exposure and Risk of Mortality of Patients with Traumatic Brain Injury: A Systematic Review and Meta-Analysis. Alcohol Clin Exp Res. 2017;41(9):1532-1540.

23. Chandrasekar A, Heuvel FO, Palmer A, Linkus B, Ludolph AC, Boeckers TM, Relja B, Huber-Lang M, Roselli F. Acute ethanol administration results in a protective cytokine and neuroinflammatory profile in traumatic brain injury. Int Immunopharmacol. 2017 Oct;51:66-75.

24. Chandrasekar A, Aksan B, Heuvel FO, Förstner P, Sinske D, Rehman R, Palmer A, Ludolph A, Huber-Lang M, Böckers T, Mauceri D, Knöll B, Roselli F. Neuroprotective effect of acute ethanol intoxication in TBI is associated to the hierarchical modulation of early transcriptional responses. Exp Neurol. 2018 Apr;302:34-45.

25. Chandrasekar A, Olde Heuvel F, Wepler M, Rehman R, Palmer A, Catanese A, Linkus B, Ludolph A, Boeckers T, Huber-Lang $M$, Radermacher P, Roselli F. The Neuroprotective Effect of Ethanol Intoxication in Traumatic Brain Injury Is Associated with the Suppression of ErbB Signaling in Parvalbumin-Positive Interneurons. J Neurotrauma. 2018 Nov 15;35(22):2718-2735.

26. Olde Heuvel F, Holl S, Chandrasekar A, Li Z, Wang Y, Rehman R, Förstner P, Sinske D, Palmer A, Wiesner D, Ludolph A, Huber-Lang M, Relja B, Wirth T, Röszer T, Baumann 
B, Boeckers T, Knöll B, Roselli F. STAT6 mediates the effect of ethanol on neuroinflammatory response in TBI. Brain Behav Immun. 2019 Oct;81:228-246.

27. Teng SX, Katz PS, Maxi JK, Mayeux JP, Gilpin NW, Molina PE. Alcohol exposure after mild focal traumatic brain injury impairs neurological recovery and exacerbates localized neuroinflammation. Brain Behav Immun. 2015;45:145-156.

28. Teng SX, Molina PE. Acute alcohol intoxication prolongs neuroinflammation without exacerbating neurobehavioral dysfunction following mild traumatic brain injury. J Neurotrauma. 2014;31(4):378-386.

29. Flierl MA, Stahel PF, Beauchamp KM, Morgan SJ, Smith WR, Shohami E. Mouse closed head injury model induced by a weight-drop device. Nat Protoc. 2009;4(9):1328-37.

30. Dorst J, Schuster J, Dreyhaupt J, Witzel S, Weishaupt JH, Kassubek J, Weiland U, Petri S, Meyer T, Grehl T, Hermann A, Jordan B, Grosskreutz J, Zeller D, Boentert M, Schrank B, Prudlo J, Winkler AS, Gorbulev S, Roselli F, Dupuis L, Otto M, Ludolph AC. Effect of high-caloric nutrition on serum neurofilament light chain levels in amyotrophic lateral sclerosis. J Neurol Neurosurg Psychiatry. 2020 Sep;91(9):10071009.

31. Ahmed F, Gyorgy A, Kamnaksh A, Ling G, Tong L, Parks S, Agoston D. Time-dependent changes of protein biomarker levels in the cerebrospinal fluid after blast traumatic brain injury. Electrophoresis. 2012 Dec;33(24):3705-11.

32. Goetzl EJ, Elahi FM, Mustapic M, Kapogiannis D, Pryhoda M, Gilmore A, Gorgens KA, Davidson B, Granholm AC, Ledreux A. Altered levels of plasma neuron-derived exosomes and their cargo proteins characterize acute and chronic mild traumatic brain injury. FASEB J. 2019 Apr;33(4):5082-5088. 
33. Park DW, Park SH, Hwang SK. Serial measurement of S100B and NSE in pediatric traumatic brain injury. Childs Nerv Syst. 2019;35(2):343-348.

34. Shahim P, Politis A, van der Merwe A, Moore B, Chou YY, Pham DL, Butman JA, DiazArrastia R, Gill JM, Brody DL, Zetterberg H, Blennow K, Chan L. Neurofilament light as a biomarker in traumatic brain injury. Neurology. 2020 Aug 11;95(6):e610-e622.

35. Shahim P, Tegner Y, Marklund N, Blennow K, Zetterberg H. Neurofilament light and tau as blood biomarkers for sports-related concussion. Neurology. 2018;90(20):e1780-e1788.

36. Disanto G, Barro C, Benkert P, Naegelin Y, Schädelin S, Giardiello A, Zecca C, Blennow K, Zetterberg H, Leppert D, Kappos L, Gobbi C, Kuhle J; Swiss Multiple Sclerosis Cohort Study Group. Serum Neurofilament light: A biomarker of neuronal damage in multiple sclerosis. Ann Neurol. 2017 Jun;81(6):857-870.

37. Gaetani L, Blennow K, Calabresi P, Di Filippo M, Parnetti L, Zetterberg $H$. Neurofilament light chain as a biomarker in neurological disorders. J Neurol Neurosurg Psychiatry. 2019;90(8):870-881.

38. Haque A, Polcyn R, Matzelle D, Banik NL. New Insights into the Role of NeuronSpecific Enolase in Neuro-Inflammation, Neurodegeneration, and Neuroprotection. Brain Sci. 2018;8(2):33. Published 2018 Feb 18.

39. Bergman J, Dring A, Zetterberg H, Blennow K, Norgren N, Gilthorpe J, Bergenheim T, Svenningsson A. Neurofilament light in CSF and serum is a sensitive marker for axonal white matter injury in MS. Neurol Neuroimmunol Neuroinflamm. 2016 Aug $2 ; 3(5): e 271$

40. Albrecht JS, Afshar M, Stein DM, Smith GS. Association of Alcohol With Mortality After Traumatic Brain Injury. Am J Epidemiol. 2018;187(2):233-241. 
41. Ouali Alami N, Tang L, Wiesner D, Commisso B, Bayer D, Weishaupt J, Dupuis L, Wong P, Baumann B, Wirth T, Boeckers TM, Yilmazer-Hanke D, Ludolph A, Roselli F. Multiplexed chemogenetics in astrocytes and motoneurons restore blood-spinal cord barrier in ALS. Life Sci Alliance. 2020 Sep 8;3(11):e201900571.

42. Jiao X, He P, Li Y, Fan Z, Si M, Xie Q, Chang X, Huang D. The Role of Circulating Tight Junction Proteins in Evaluating Blood Brain Barrier Disruption following Intracranial Hemorrhage. Dis Markers. 2015;2015:860120.

43. Zhu JC, Si MY, Li YZ, Chen HZ, Fan ZC, Xie QD, Jiao XY. Circulating tight junction proteins mirror blood-brain barrier integrity in leukaemia central nervous system metastasis. Hematol Oncol. 2017 Sep;35(3):365-373.

44. Lindblad C, Nelson DW, Zeiler FA, Ercole A, Ghatan PH, von Horn H, Risling M, Svensson M, Agoston DV, Bellander BM, Thelin EP. Influence of Blood-Brain Barrier Integrity on Brain Protein Biomarker Clearance in Severe Traumatic Brain Injury: A Longitudinal Prospective Study. J Neurotrauma. 2020 Jun 15;37(12):1381-1391.

45. Kerr N, Lee SW, Perez-Barcena J, Crespi C, Ibañez J, Bullock MR, Dietrich WD, Keane RW, de Rivero Vaccari JP. Inflammasome proteins as biomarkers of traumatic brain injury. PLoS One. 2018 Dec 31;13(12):e0210128.

46. Halford J, Shen S, Itamura K, Levine J, Chong AC, Czerwieniec G, Glenn TC, Hovda DA, Vespa P, Bullock R, Dietrich WD, Mondello S, Loo JA, Wanner IB. New astroglial injury-defined biomarkers for neurotrauma assessment. J Cereb Blood Flow Metab. 2017 Oct;37(10):3278-3299. 


\section{Figure legends}

\section{Figure 1: TBI does not affect ethanol concentration after binge administration}

Blood alcohol concentration in blood plasma $3 \mathrm{~h}$ after TBI, 4 treatment groups were used; saline-sham (SS), Ethanol-sham (ES), saline-TBI (ST) and ethanol-TBI (ET). Ethanol treatment showed a significant difference between treatment groups $(p<0.0001)$. Post-hoc analysis revealed a significant difference between SS and ES $(p<0.0003)$ and between ST and ET $(p<$ 0.0001). However, ES and ET showed no difference ( $p>0.9999)$. Boxplots represent median value, 25th to 75 th percentile (box), min to max (whiskers), including individual data points.

Group size: $\mathrm{SS}, \mathrm{N}=8$; ES, $\mathrm{N}=14 ; \mathrm{ST}, \mathrm{N}=24 ; \mathrm{ET}, \mathrm{N}=17$ * $^{*}: \mathrm{p}<0.05 ;{ }^{* *}: \mathrm{p}<0.01 ; * * *: \mathrm{p}<$ $0.001 ; * * * *: p<0.0001$ 


\section{Figure 2: Ethanol does not affect NFL levels post TBI}

NFL concentration was assessed 3h post TBI and Ethanol TBI, 4 treatment groups were used; saline-sham (SS), Ethanol-sham (ES), saline-TBI (ST) and ethanol-TBI (ET). A) Treatment groups showed significant differences in NFL concentration $(p<0.0001)$. Post-hoc analysis showed a significant difference between SS and ST $(p=0.0005)$ but no difference between ST and ET ( $p>0.9999)$. B) Correlation analysis showed no significant relationship between $N F L$ and ethanol in the ET group $\left(R^{2}=0.0170 ; p=0.6306\right)$. Boxplots represent median value, 25th to 75th percentile (box), min to max (whiskers), including individual data points. Correlation with linear regression is shown. Group size: $\mathrm{SS}, \mathrm{N}=8$; $\mathrm{ES}, \mathrm{N}=14 ; \mathrm{ST}, \mathrm{N}=24$; $E T, \mathrm{~N}$ $=17 *^{*}: \mathrm{p}<0.05 ; * *: \mathrm{p}<0.01 ; * * *: \mathrm{p}<0.001 ; * * * *: \mathrm{p}<0.0001$.

\section{Figure 3: Ethanol decreases NSE levels post TBI}

NSE concentration was assessed 3h post TBI and Ethanol TBI, 4 treatment groups were used; saline-sham (SS), Ethanol-sham (ES), saline-TBI (ST) and ethanol-TBI (ET). A) NSE concentration showed significant differences between treatment groups $(p=0.0232)$. Posthoc analysis revealed a significant difference between SS and ST ( $p=0.0295$ ), but not between ST and ET ( $p>0.9999)$. B) Correlation analysis revealed a significant inverse correlation between NSE and ethanol in the ET group $\left(R^{2}=0.4069 ; p<0.0078\right)$. C) Slope comparison revealed no significant difference in the treatment groups between NFL and NSE $(F=0.4236 ; p=0.7368)$, correlation within the groups showed no difference (NSE vS NFL SS: $R^{2}=0.0503 ; p=0.6306, E S: R^{2}=0.0003 ; p=0.0954, S T: R^{2}=0.0918 ; p=0.1600, E T: R^{2}=$ 0.0118; $p=0.6893$ ). Boxplots represent median value, 25 th to 75 th percentile (box), $\min$ to max (whiskers), including individual data points. Correlation with linear regression is shown. 
Group size: $\mathrm{SS}, \mathrm{N}=8$; $\mathrm{ES}, \mathrm{N}=14 ; \mathrm{ST}, \mathrm{N}=24 ; \mathrm{ET}, \mathrm{N}=17$. $^{*}: \mathrm{p}<0.05 ; * *: \mathrm{p}<0.01 ; * * *: \mathrm{p}<$ $0.001 ; * * *: p<0.0001$

\section{Figure 4: BBB disruption post TBI is unaffected by ethanol}

Concentration of Claudin-5 was assessed in the blood 3 h post TBI and ethanol TBI, 4 treatment groups were used; saline-sham (SS), Ethanol-sham (ES), saline-TBI (ST) and ethanol-TBI (ET). A) Treatment groups revealed significant differences in Claudin-5 concentration $(p=0.0047)$. Post-hoc analysis revealed significant differences between ES and ST ( $p=0.0157)$ but no difference in ST and ET ( $p>0.9999)$. B) Correlation analysis between Claudin-5 and ethanol showed no difference in the ET group $\left(R^{2}=0.0215 ; p=\right.$ 0.5747). Boxplots represent median value, 25th to 75th percentile (box), $\min$ to $\max$ (whiskers), including individual data points. Correlation with linear regression is shown. Group size: SS, $N=8$; ES, $N=14 ; \mathrm{ST}, \mathrm{N}=24$; ET, $\mathrm{N}=17 .^{*}: \mathrm{p}<0.05 ;{ }^{* *}: \mathrm{p}<0.01 ; * * *: \mathrm{p}<$ $0.001 ; * * * *: p<0.0001$

\section{Figure 5: NFL levels are correlated to BBB disruption}

Claudin-5 levels were correlated with both NSE and NFL concentration $3 \mathrm{~h}$ post TBI and ethanol TBI, 4 treatment groups were used; saline-sham (SS), Ethanol-sham (ES), saline-TBI (ST) and ethanol-TBI (ET). A) Slope comparison revealed no significant difference in the treatment groups between NSE and Claudin-5 ( $F=0.9541 ; p=0.4207)$, correlation of NSE and Claudin-5 levels was very poor in each of the four treatment groups (SS: $R^{2}=0.0379 ; p=$ 0.6757, ES: $\left.R^{2}=0.0001 ; p=0.9716, S T: R^{2}=0.0470 ; p=0.3455, E T: R^{2}=0.1597 ; p=0.1251\right)$.

B) Slope comparison revealed significant difference in the treatment groups between NFL 
and Claudin-5 ( $F=3.157 ; p=0.0320)$, correlation of NSE and Claudin-5 levels were significant in the ST group $\left(R^{2}=0.2545 ; p=0.0276\right)$ but not in the other treatment groups $\left(S S: R^{2}=\right.$ $\left.0.5546 ; p=0.0548, E S: R^{2}=0.0512 ; p=0.4571, E T: R^{2}=0.0136 ; p=0.6785\right)$ and a significant difference between the ST and ET group ( $p=0.0303$ ). Correlation with linear regression is shown. Group size: SS, N = 8; ES, N = 14; ST, N = 24; ET, $N=17 .^{*}: p<0.05 ; * *: p<0.01 ; * * *$ $: p<0.001 ; * * * *: p<0.0001$ 
bioRxiv preprint doi: https://doi.org/10.1101/2020.09.18.303396; this version posted September 20, 2020. The copyright holder for this preprint (which was not certified by peer review) is the author/funder, who has granted bioRxiv a license to display the preprint in perpetuity. It is made available under aCC-BY-NC-ND 4.0 International license.

\section{Figure 1}

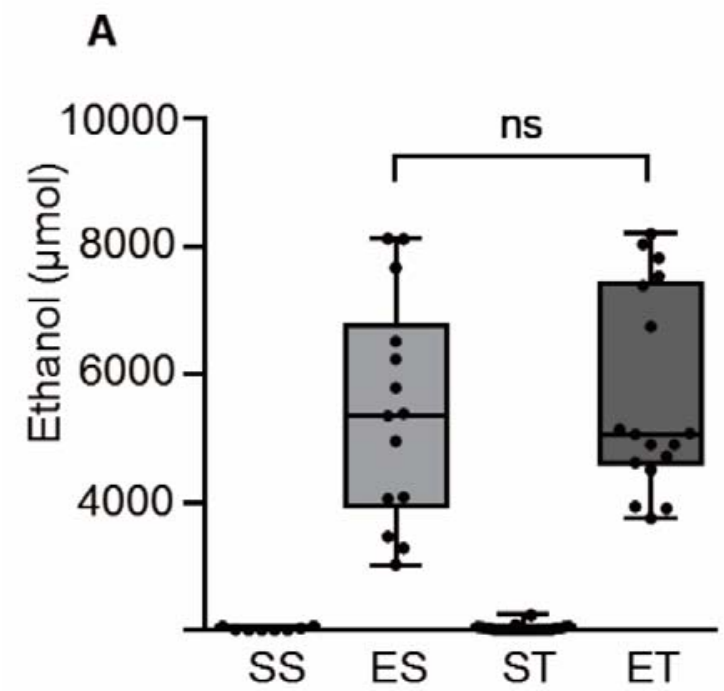


bioRxiv preprint doi: https://doi.org/10.1101/2020.09.18.303396; this version posted September 20, 2020. The copyright holder for this preprint (which was not certified by peer review) is the author/funder, who has granted bioRxiv a license to display the preprint in perpetuity. It is made available under aCC-BY-NC-ND 4.0 International license.

Figure 2

A

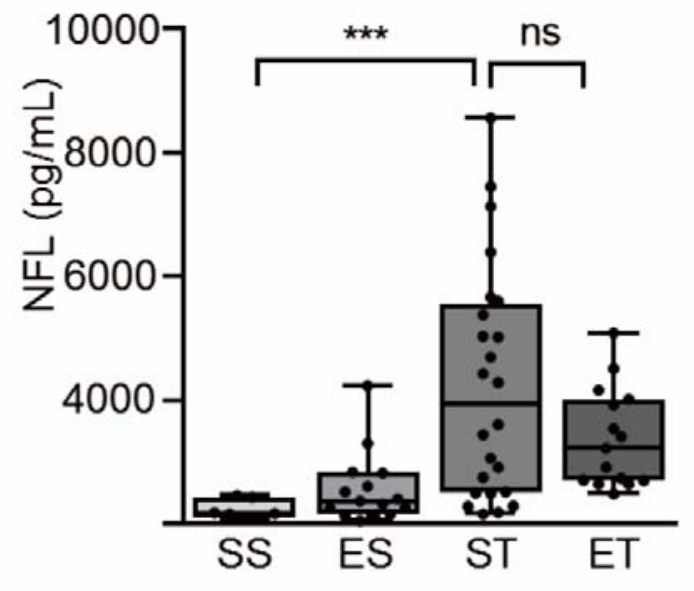

B

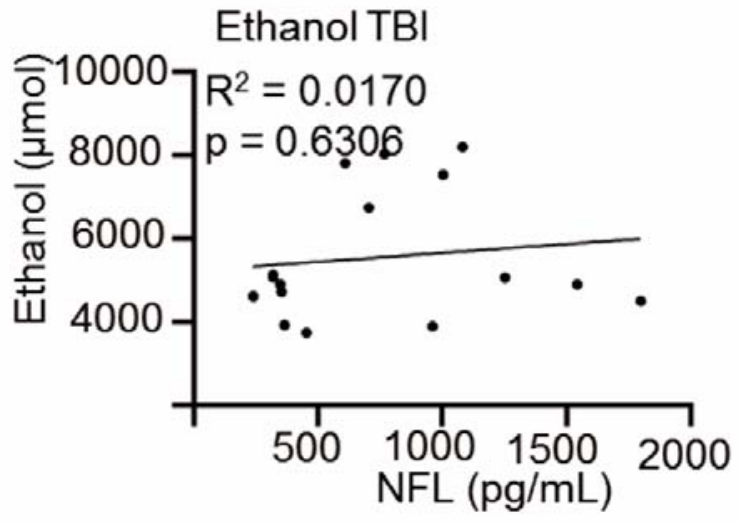


Figure 3

A B
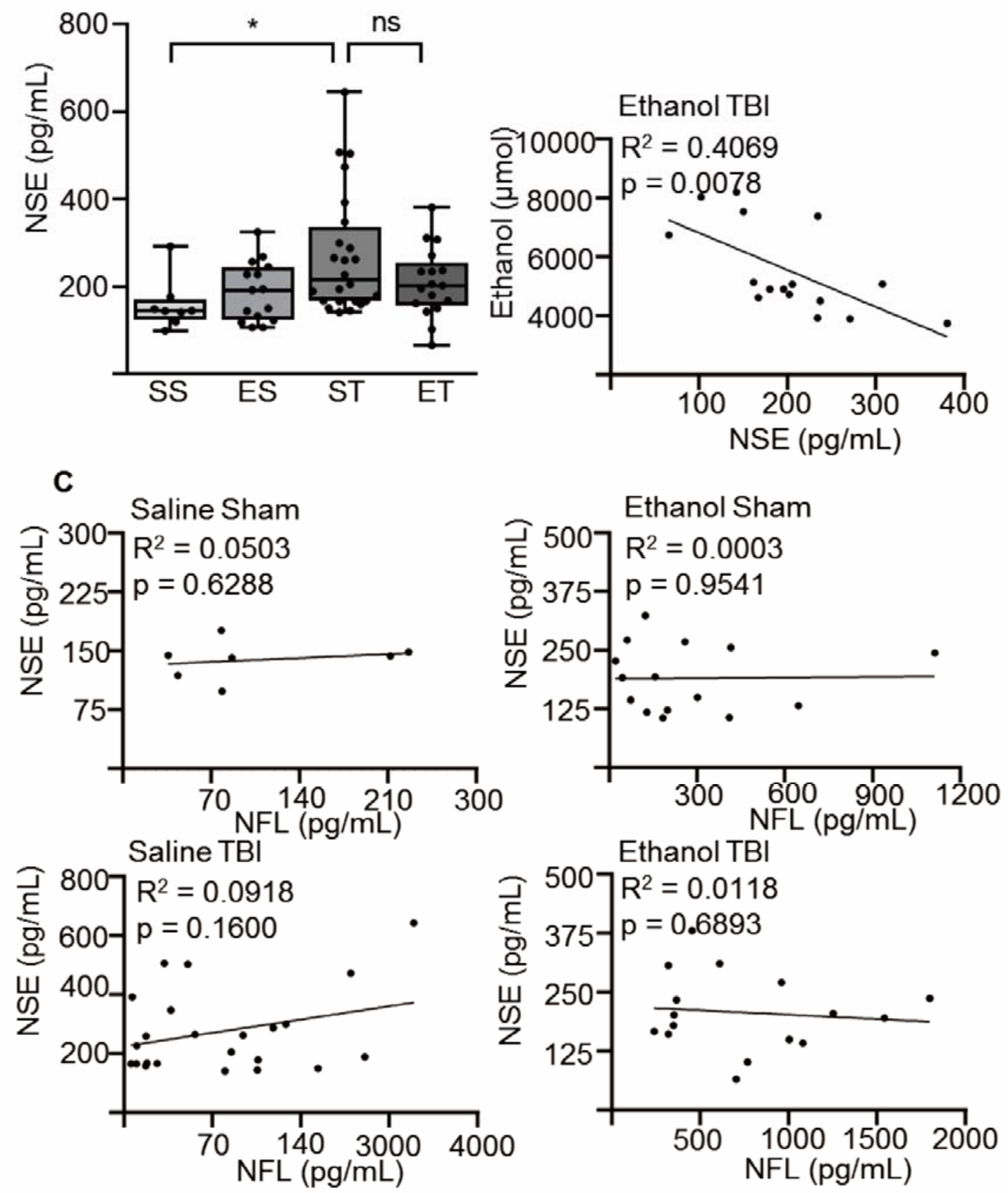
bioRxiv preprint doi: https://doi.org/10.1101/2020.09.18.303396; this version posted September 20, 2020. The copyright holder for this preprint (which was not certified by peer review) is the author/funder, who has granted bioRxiv a license to display the preprint in perpetuity. It is made available under aCC-BY-NC-ND 4.0 International license.

Figure 4

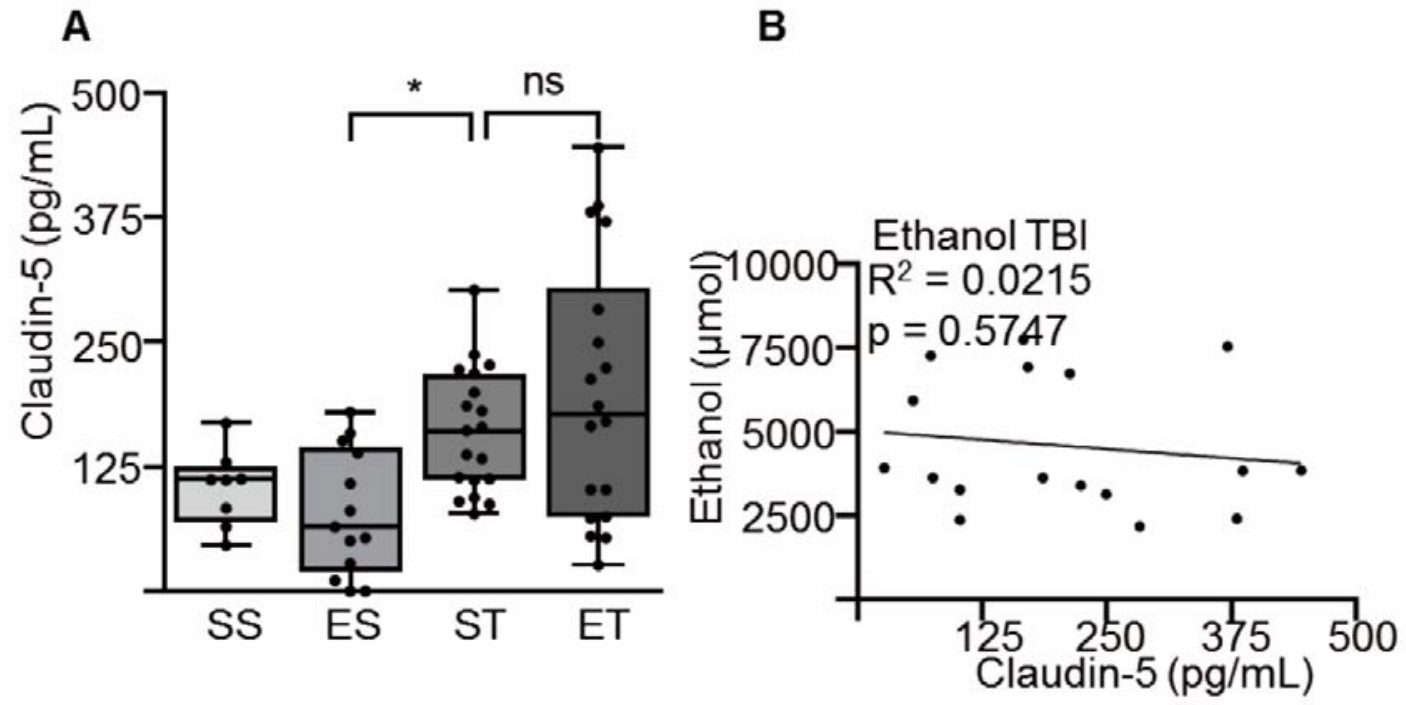


Figure 5
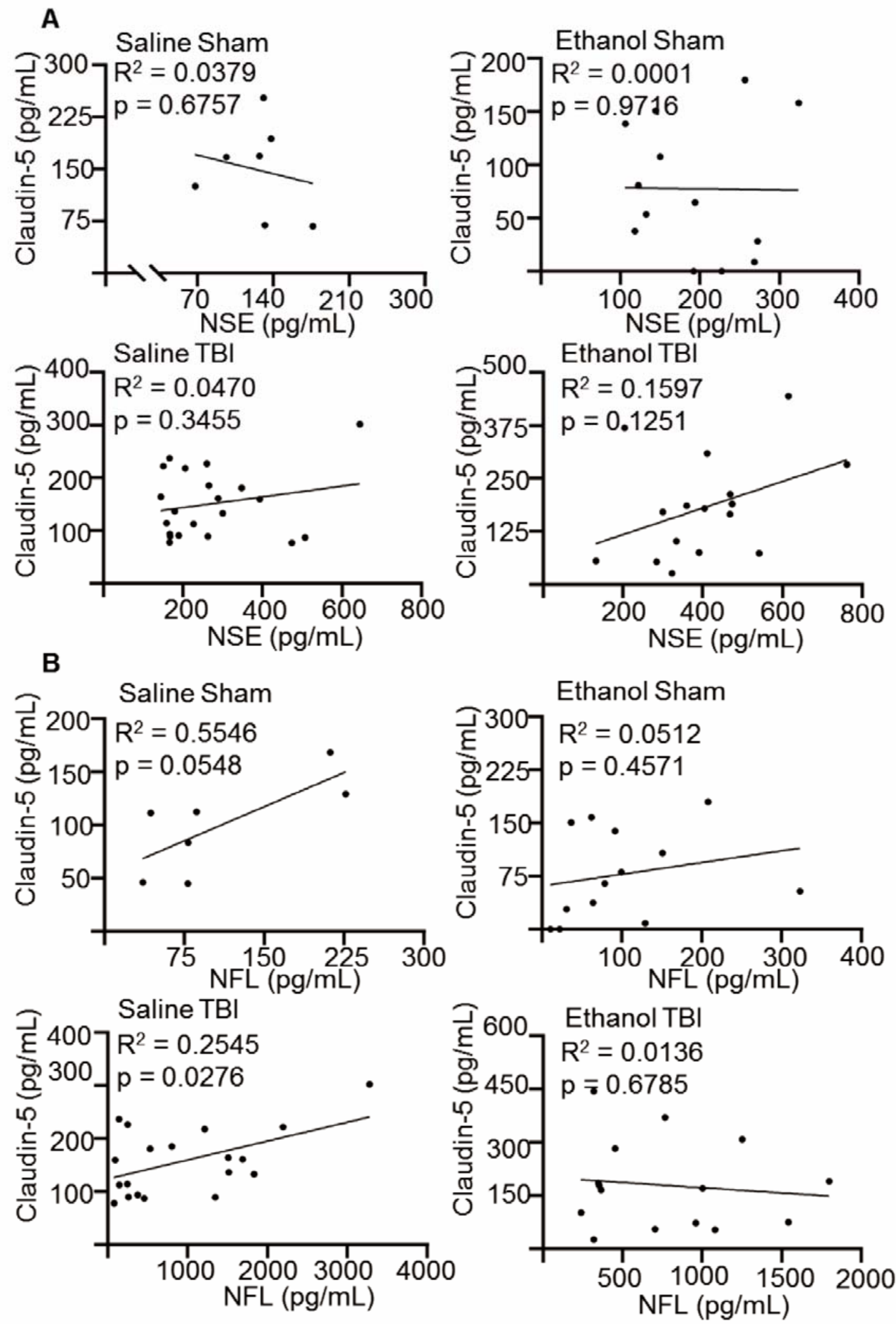